\title{
Environmental impact of nano-functionalized construction materials: leaching of titanium and nitrates from photocatalytic pavements under outdoor conditions
}

\author{
Eva Jimenez-Relinque, Maria Grande, Teresa Duran, Ángel Castillo, Marta Castellote* \\ Institute for Construction Sciences Eduardo Torroja, IETcc-CSIC, Serrano Galvache 4, 28033 Madrid, Spain
}

\section{H I G H L I G H T S}

- Evaluation of side effects of photocatalytic pavements to aquatic ecosystems

- $\mathrm{TiO}_{2}$ nanoparticles leached from photocatalytic pavements

- Nitrates due to photocatalytic processes collected in rainwater

- Monitoring in real outdoor conditions 7 different materials for more than 800 days

\section{A R T I C L E I N F O}

\section{Article history:}

Received 21 April 2020

Received in revised form 6 July 2020

Accepted 6 July 2020

Available online 8 July 2020

\section{Keywords:}

$\mathrm{TiO}_{2}$

Nanoparticle

Harmful

Environment

Leaching

Nitrates

Construction materials

Eutrophication
G R A P H I C A L A B S T R A C T

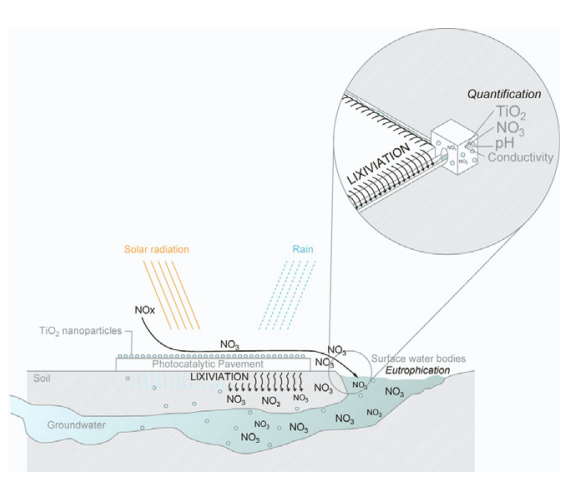

\begin{abstract}
A B S T R A C T
There is a growing use of nano-functionalized construction materials, which contain nanoparticles embedded in their bulk or deposited on their surfaces. In the case of photocatalytic materials, nano- $\mathrm{TiO}_{2}$ is usually added to provide it's functionality. One concern about these materials, in addition to release of nanoparticles as airborne, is that they can be leached into the aquatic environment. Moreover, water eutrophication could be caused due to the increase in $\mathrm{NO}_{3}^{-}$as a product of the photocatalytic oxidation of NOx in runoff. In this paper, a systematic long term campaign assessing these potential side effects in the real outdoor environment has been carried out. Rainwater leachates from $4 \mathrm{~m}^{2}$ slabs of 7 different photocatalytic materials exposed outdoors in two different locations (platforms) were collected and analysed over more than 800 days. $\mathrm{Ti} \mathrm{NO}_{3}^{-}, \mathrm{pH}$ and conductivity were analysed. Ti was found in the leachates of almost every material, without a clear relation with the type of application (percolated cementitious slurry, suspension/emulsion or $\mathrm{TiO}_{2}$ built-in). The highest concentration found was of $60 \mu \mathrm{g} / \mathrm{L}$, which seems to be rather small when comparing with some threshold values for drinking water. In all the cases, the detected $\mathrm{TiO}_{2}$ nanoparticles from water leachates were embedded in large microparticle agglomerates coming from the construction material matrix, which are less dangerous than nanoparticles. Nitrates were leached in clear relation with the NOx oxidation photocatalytic performance, and the observed concentrations were not higher than those in the recycled water used by the Madrid City Council to clean the streets.
\end{abstract}

(c) 2020 Elsevier B.V. All rights reserved.

\footnotetext{
* Corresponding author.

E-mail address: martaca@ietcc.csic.es (M. Castellote).
}

\section{Introduction}

The incorporation of nanoparticles into construction materials is an increasing tendency. Among the different functionalities introduced 
by nanoparticles, photocatalysis (Fujishima and Honda, 1972), by incorporation of nanosemiconductors, mainly $\mathrm{TiO}_{2}$, in the materials, has developed over the last few decades as a promising technology to remediate air quality (Bengtsson and Castellote, 2014; Cassar, 2004; Chen and Poon, 2009; Hüsken, 2009; Bengtsson and Castellote, 2010; Dillert et al., 2013; Jimenez-Relinque and Castellote, 2014; Sánchez et al., n.d.; Jiménez-Relinque et al., 2019), self-sterilize (Goswami et al., 1997; Sikora et al., 2017), self-clean (Bengtsson and Castellote, 2014; Folli et al., 2009; Peruchon et al., 2009; Folli et al., 2012; Diamanti et al., 2013), impart anti-fog capabilities (Cannavale et al., 2010), degrade pollen and allergens (Sapiña et al., 2013; JimenezRelinque et al., 2016; Sapiña et al., 2017) and remove soot (Smits et al., 2013).

However, the benefits of adding nanoparticles to construction materials are starting to be offset by concerns about possible unwanted effects (Chapman, 2006; Bystrzejewska-Piotrowska et al., 2009; Dwivedi et al., 2015; Buzea et al., 2007; Pacheco-Blandino et al., 2012). It is becoming clear that in addition to the advantages, there are some drawbacks of using nanotechnology mainly related to the nanoparticles potential to behave as harmful environmental contaminants after their release; although not conclusive in humans, there are experimental evidences that ultrafine particles are causally involved in adverse responses seen in sensitive humans (Zhu et al., 2004; Pacheco-Torgal and Jalali, 2011; Jayapalan et al., 2013). Even though they are not aerosolized, nanoparticles may be released in other media, such as in water runoff, affecting aquatic ecosystems (Lovern et al., 2007; Federici et al., 2007), which are especially vulnerable due to the potential of pollutant mixing and dispersal. Another possible unwanted effect of the use of photocatalysts in construction is the potential for water eutrophication due to the increase in $\mathrm{NO}_{3}^{-}$in the water runoff (Devahasdin et al., 2003; Herrmann, 1999; Ansari et al., 2010), which is the product of the photocatalytic oxidation of NOx.

Despite the several studies on different aspects of photocatalytic construction materials, only a few papers address the leaching of $\mathrm{Ti}$ and the production of $\mathrm{NO}_{3}^{-}$. To the best of the authors' knowledge, the first data of leached Ti from photocatalytic construction materials under natural wear were reported by Kägi et al. (2008), who described concentrations of $\mathrm{Ti}$ in the runoff of a new facade as high as $600 \mu \mathrm{g} / \mathrm{L}$ over the period of one complete rain event. No other paper addressing leached Ti from photocatalytic construction materials under natural exposure has been found. There are some reports of laboratory trials on the leaching of photocatalytic construction materials. In Olabarrieta et al. (2012), in accelerated ageing under a water flow of two different photocatalytic coatings, $\mathrm{TiO}_{2}$ concentrations of up to $150.5 \mu \mathrm{g} / \mathrm{L}$ were found. Al-Kattan, 2013 investigated the release of Ti from panels covered in paint with and without nanoTiO ${ }_{2}$ that were exposed to simulated weathering by sunlight and rain in climate chambers and observed a very low release that was close to background values. Zuin et al. (2014) performed leaching tests of $\mathrm{TiO}_{2}, \mathrm{Ag}$ and $\mathrm{SiO}_{2}$ nanoparticles contained in experimental water-borne paints by using a permanent immersion procedure and reported "a very low release of Ti (4-8 $\mu \mathrm{g} / \mathrm{L})$ ". Shandilya et al. (2015), after conducting experiments in a weathering chamber, also concluded that despite deterioration by weathering, the nanocoated sample surfaces were still strong enough to resist leaching of the constituent nanoparticles into the runoff water. Bossa et al. (2017) performed leaching of photocatalytic cement pastes simulating "a worst case scenario", and after $168 \mathrm{~h}$ of leaching, the total Ti released was $33.3 \pm 5.1 \mathrm{mg} \mathrm{Ti} / \mathrm{m}^{2}$ of cement for pastes with a water/cement ratio of 0.5 .

From these results, it can be observed that there is relatively high variation in previous data, which can be attributed to the differences between the samples and the experimental procedures used. In most of these studies, samples were analysed by inductively couple plasma (ICP) techniques. As stated in Kägi et al. (2008) and demonstrated in Gibson et al. (2006), Goodall et al. (1993), Halicz et al. (1993), Wang (2005) and Wu et al. (2007) for $\mathrm{Al}_{2} \mathrm{O}_{3}, \mathrm{SiO}_{2}$ and $\mathrm{TiO}_{2}$, particles $<1.5 \mu \mathrm{m}$ behave similarly in aqueous solutions and in an ICP source under standard hot plasma conditions. This implies that the recovery rates of the samples might have been artificially low due to incomplete ionization of particles $>1.5 \mu \mathrm{m}$ in the plasma. However, the recovery of Ti nanoparticles could be considered complete when analysed with ICP techniques. Concerning the leaching of nitrates, in (Dylla and Hassan, 2014), $\mathrm{TiO}_{2}$ nanoparticles and nitrates were measured after $4.5 \mathrm{~h}$ of photocatalytic oxidation of $\mathrm{NO}_{\mathrm{x}}$ using environmentally relevant conditions, and $49 \%$

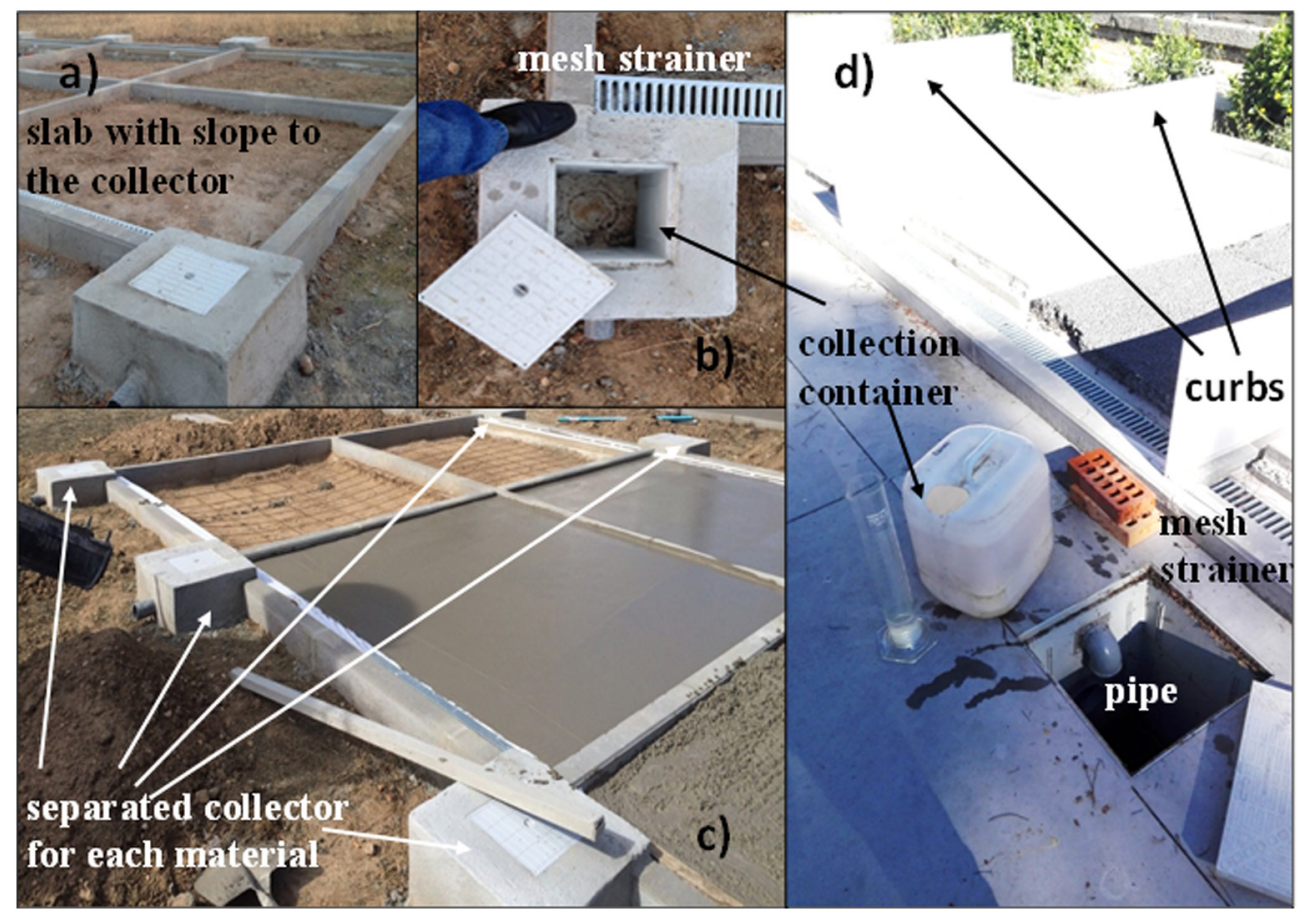

Fig. 1. Details of the water collection system on the leaching workbenches (a-c) AR-P and (d) M-P. 

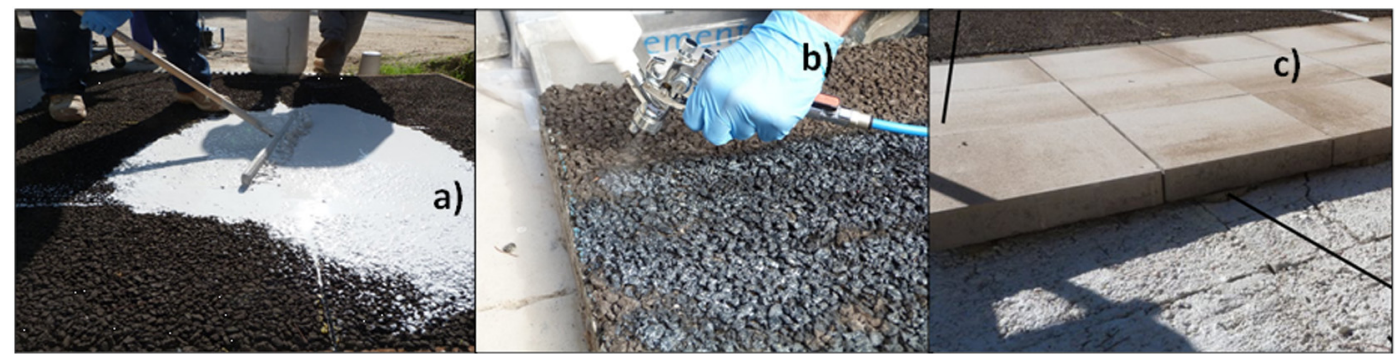

Fig. 2. Application of photocatalytic materials on slabs: (a) cement slurries (A and B) (b) emulsions (C, D and E), and (c) built-in photocatalytic tiles (F and G).

of the theoretical amount of produced nitrates in water was recovered, while Ti was not detected in any of the samples. In (Hassan et al., 2012), the presence of nitrates was correlated with the activity of permeable pavement under different environmental conditions.

Experiments reflecting the authentic outdoor exposure of photocatalytic construction materials as exposed to different factors taking place during natural weathering, such as time, rain, freeze-thaw cycling, drying and saturation, wind, natural irradiation or other damaging agents, have not been found in the literature.

Within this context, as pioneering research, the aim of this paper is to asses the potential side effects of nanoparticles leaching, as well as possible release of nitrates generated by the photocatalytic oxidation of air nitrogen oxide, associated to the use of photocatalytic construction technologies in the real outdoor environment. Monitoring of the leachates in rainwater after coming into contact with $4 \mathrm{~m}^{2}$ slabs of 7 different photocatalytic materials exposed outdoors in two different locations was carried out for 800 days $\mathrm{pH}$, conductivity and the amount of Ti and $\mathrm{NO}_{3}^{-}$for each material were analysed.

\section{Materials and methods}

\subsection{Testing site}

This research was framed within the LIFE-PHOTOSCALING project (LIFE 13/ENV/ES/001221), where duplicate demonstration platforms were constructed on a pilot scale (www.lifephotoscaling.eu). Both platforms were located at the premises of the IETcc-CSIC, one of them in the north of the city of Madrid (M-P) and the other in the city of Arganda del Rey (AR-P) in the region of Madrid. Each platform consisted of 3 workbenches (leaching, abrasion and natural exposure), each of which contained sets of slabs of photocatalytically active materials exposed outdoors. The results reported in this paper were carried out on the leaching workbenches.

The leaching workbenches were composed up of $4 \mathrm{~m}^{2}$ slabs of different photocatalytic materials. The leaching workbenches were constructed with a slight slope to drive the leachates through a mesh strainer to a pipe that channelled them into an individual collector for each material. The different materials were limited by curbs so that runoff coming from different tests and rainwater were not mixed between the different materials (see Fig. 1).

7 photocatalytic materials were installed between October and November 2016 in both platforms, and leaching samples were taken immediately after installation until February 2019.

The types of material tested were the following:

I. Photocatalytic slurries percolated on asphalt substrates (slabs A and B)

II. Photocatalytic suspensions/emulsions sprayed on asphalt and cementitious tiles (slabs C, D and E)

III. Factory-supplied photocatalytic tiles with $\mathrm{TiO}_{2}$ built-in (slabs $\mathrm{F}$ and $\mathrm{G}$ )

A reference slab from plain, non-photocatalytic concrete (Ref) was also incorporated in both leaching workbenches.
In Fig. 2, examples of the application of the photocatalytic materials are given. The materials were labelled from $A$ to $G$ without identifying them specifically for confidentiality reasons.

\subsection{Procedure}

\subsubsection{Leachate collection and analysis}

Rain runoff from each of the slabs on the leaching workbenches was collected separately in plastic containers (see Fig. 1d) and analysed to evaluate the Ti and $\mathrm{NO}_{3}^{-}$contents, $\mathrm{pH}$ and conductivity for 800 days. Samples were also collected from plain, non-photocatalytic concrete (Ref) for the last 300 days of the study.

In addition to the rainwater, on three different occasions, high-pressure water cleaning in the streets of Madrid was recreated at the M-P site (Fig. 3). Madrid City Council (MCC) staff conducted the high-pressure water cleaning using a real pressurized water tank truck. The water pressure was obtained with a pump (Zeda pump zh $40,40-45 \mathrm{~m}^{3} / \mathrm{h}, 8$ bar).

Ti was analysed using a Varian 725 ICP-optical emission spectrometry (OES) instrument at a $1.25 \mathrm{~kW}$ power and a $15 \mathrm{~L} / \mathrm{min}$ flux of plasma. Nitrates were analysed colorimetrically using a UV/VIS spectrophotometer. To perform this measurement, a VISOCOLOR® nitrate kit was used. The VISOCOLOR $®$ nitrate kit made measurement of the nitrate concentration in water solutions through a colorimetric chemical reaction. The nitrates were reduced to nitrite with an inorganic reducing agent. Nitrite was then diazotized with an aromatic amine and simultaneously coupled to form an azo dye (yellow colour). Therefore, the resulting intensity of the yellow colour was directly related to the concentration of the nitrates. To perform a calibration curve for quantitative measurement of nitrates, the CIELAB b* coordinate (yellow) was used with solutions of AgNO3 at different concentrations. In addition, leachate samples were investigated using field emission scanning electron microscopy (FE-SEM) images with

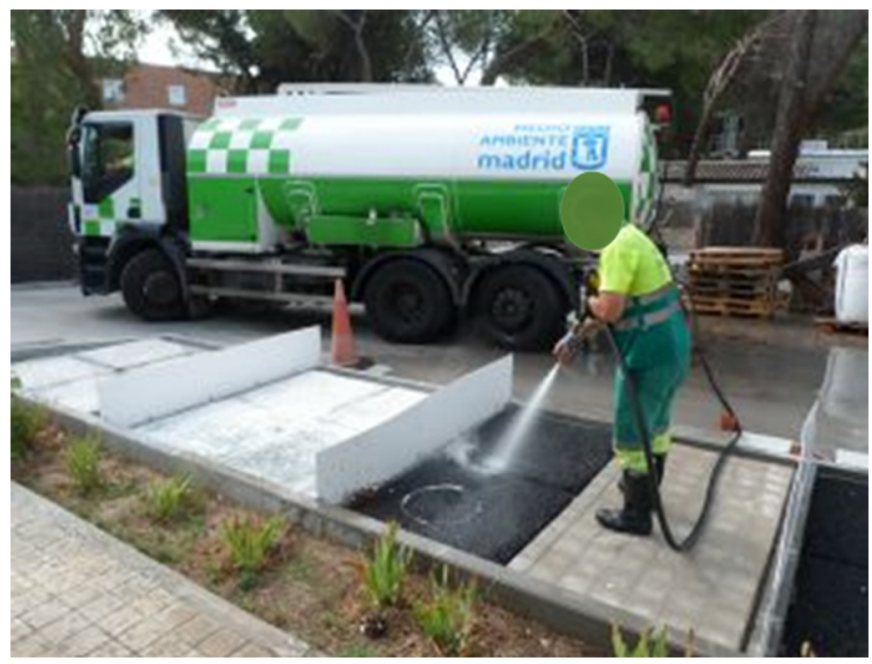

Fig. 3. High-pressure water cleaning at the Madrid platform by a staff member of the Madrid City Council. 

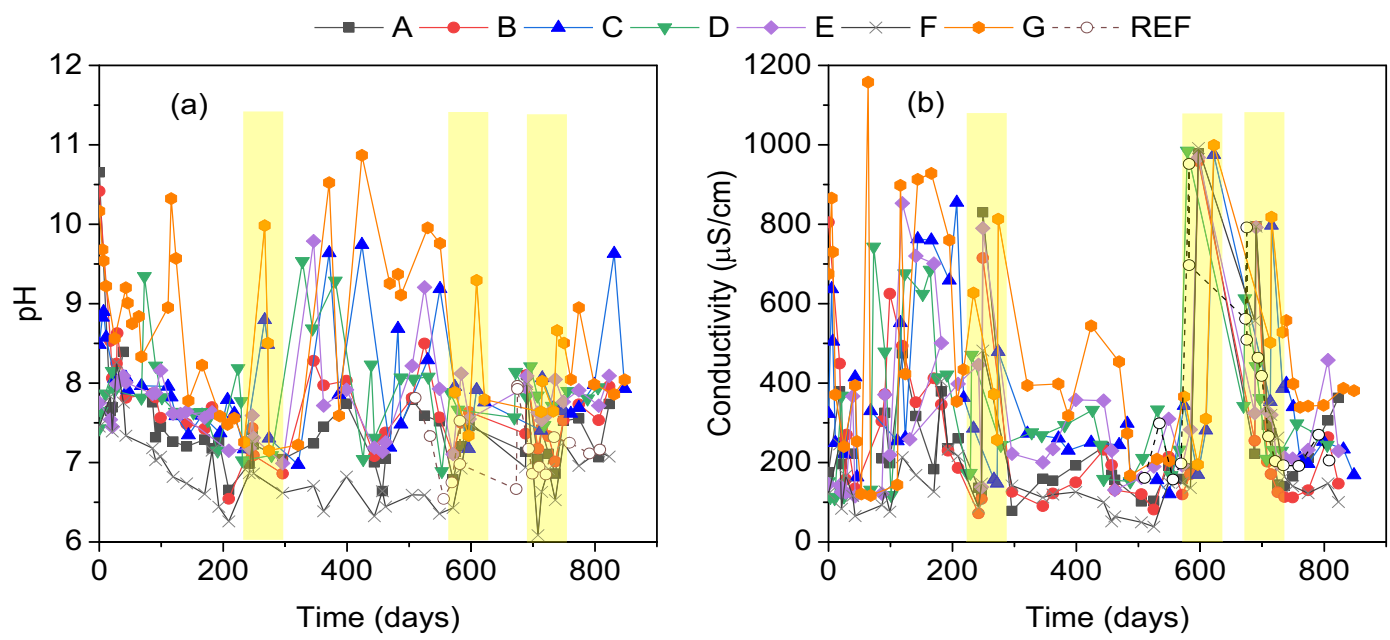

Fig. 4. Evolution of a) $\mathrm{pH}$ and b) conductivity of the runoff water collected at M-P.

energy-dispersive X-ray spectrometry (EDX) measurements to detect $\mathrm{TiO}_{2}$ micro- and nanoparticles and to determine the features of release.

\subsubsection{Measurement of NOx removal}

The photocatalytic efficiency for NOx removal $\left(\mathrm{R}_{\mathrm{NOx}}, \%\right)$ was assessed on-site at different times by means of the PhotonSite device (Jiménez-Relinque et al., 2019). The operational conditions of the tests were $450 \pm 50 \mathrm{ppb}$ of NO gas in air at a flow rate of $3 \mathrm{~L} / \mathrm{min}$ with a relative humidity $\mathrm{RH}_{\text {int }}$ inside the chamber of approximately $25 \%$. The irradiance inside the chamber was $10 \mathrm{~W} / \mathrm{m}^{2}$ (LEDs $365 \mathrm{~nm}$ ) for $15 \mathrm{~min}$. Prior to and after irradiation, the gas flow passed through the PhotonSite chamber until stabilization of the conditions. The NOx concentration of the gas was monitored using a chemiluminescence analyser (AC-32 M, Environment S.A.). The pavement was not preconditioned prior to the measurements. Additionally, $\mathrm{R}_{\mathrm{NOx}}(\%)$ was measured at the time of application of photocatalytic materials at the laboratory according to the standard ISO 22197-1:2007.

\section{Results and discussion}

\section{1. $\mathrm{pH}$ and conductivity}

The evolution of $\mathrm{pH}$ and conductivity of the leachates collected in the catch basins for each of the materials for M-P and AR-P are depicted in Figs. 4 and 5, respectively. In Fig. 4, the events of high-pressure water cleaning by the MCC are highlighted in yellow. The temporal point of these episodes was not the same for all materials, as they were implemented over several months. Water used by the MCC to clean the slabs was, as is usual for cleaning the city, recycled water. This can be observed in Fig. 4-b, where an increase in the conductivity of the leachates was observed at approximately 270, 600 and 700 days, corresponding to the three campaigns of high-pressure water cleaning.

Concerning $\mathrm{pH}$, the overall behaviour was quite similar on both platforms. The different materials started to leach at different $\mathrm{pH}$ values depending on their composition (B and G: above 10; A and C: approximately 8-9; and D, E and F: approximately 7.5). Then, the pH gradually and smoothly decreased at approximately 300 days, and then it increased more or less abruptly, depending on the material, stabilizing with an increasing tendency at approximately 600 days. At M-P, there were more differences in $\mathrm{pH}$ between materials than at AR-P. Only a small influence of high-pressure water cleaning was detected.

Concerning conductivity (corrected at $25^{\circ} \mathrm{C}$ ), the evolution over time was similar at both platforms if the high values of conductivity observed for the water used by the MCC during high-pressure water cleaning was not taken into account. The conductivity increased initially and reached a kind of maximum at approximately 150-200 days and then decreased, exhibiting a period of low conductivity for approximately 100 days for every material; the conductivity increased during the subsequent approximately 100 days and then decreased again. At both platforms, the conductivity was higher for materials $\mathrm{C}$, E and $\mathrm{G}$ than for the other materials, and the values corresponding to the reference slab were relatively low and followed the same tendency for both $\mathrm{pH}$ and conductivity.
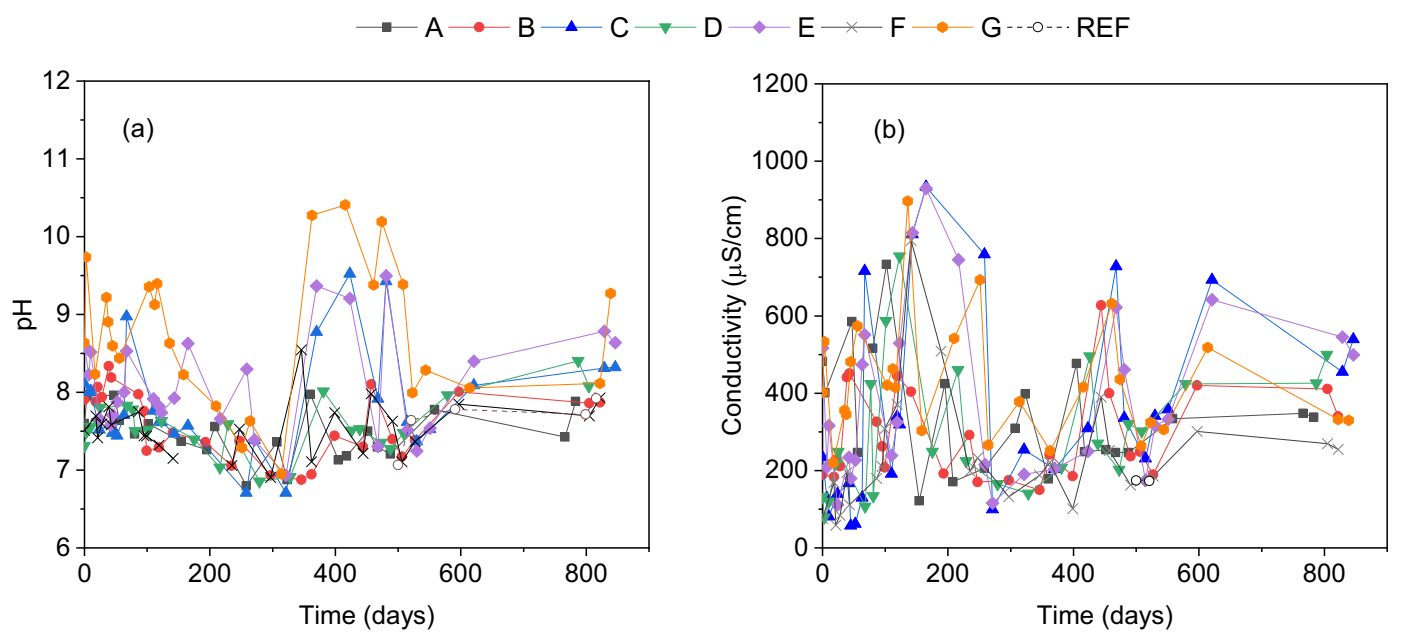

Fig. 5. Evolution of a) $\mathrm{pH}$ and b) conductivity of the runoff water collected at AR-P. 

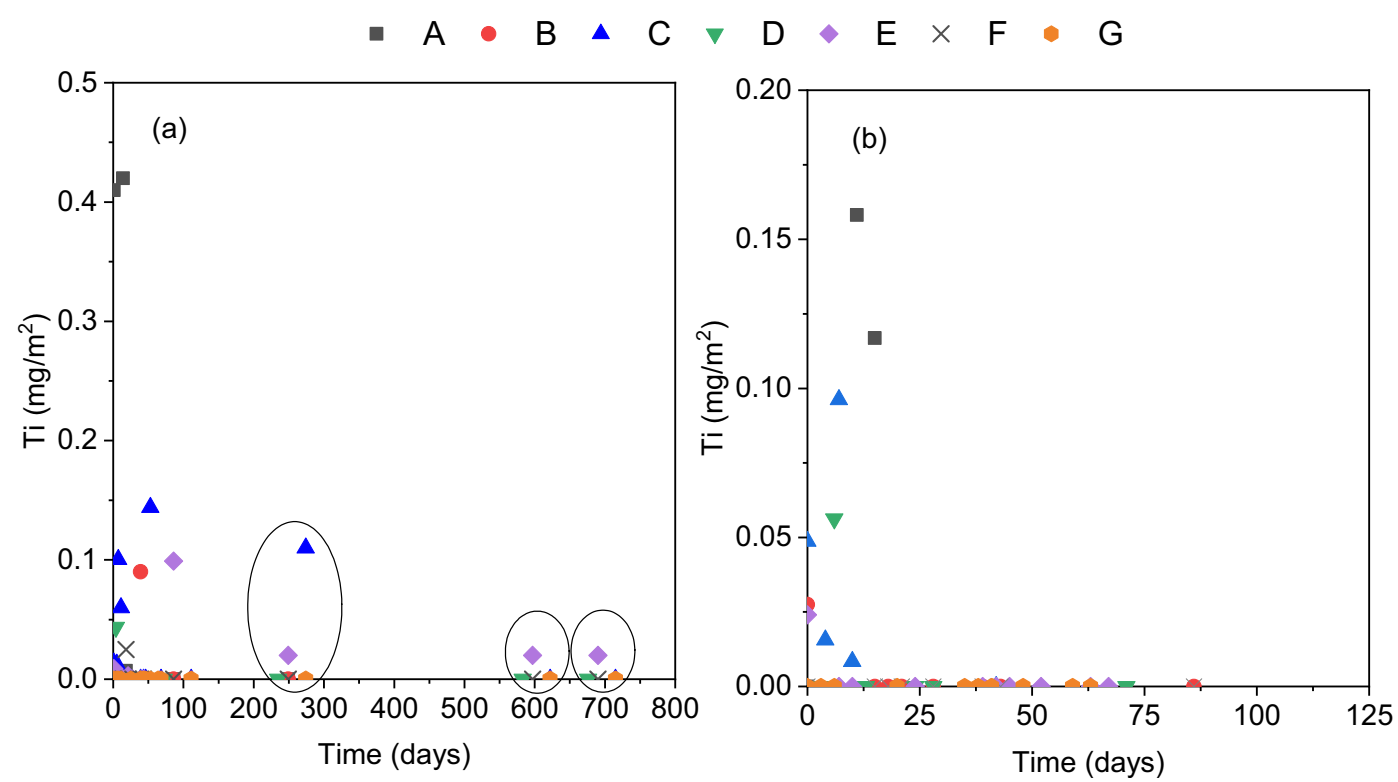

Fig. 6. Leaching of Ti from the samples at a) M-P and b) AR-P.

\subsection{Leaching of $\mathrm{Ti}$}

The results corresponding to the amount of Ti leached per unit area $\left(\mathrm{mg} / \mathrm{m}^{2}\right)$ in each of the liquid samples collected are given in Fig. 6a and b for M-P and AR-P, respectively. As stated in the introductory section, the analytical method used was expected to recover particles $<1.5 \mu \mathrm{m}$ in size. Thus, even though the amount of Ti could be underestimated, the leached nanoparticles were included in these results. Values found for the reference slab were always below the limit of detection of the analytical technique $(2 \mu \mathrm{g} / \mathrm{L})$.

For both platforms, from the 50th day, no Ti was found in the leachates, with the results always being below the detection limit of the instrument used. After 100 days, no Ti was detected with the exception of the samples taken after the high-pressure water cleaning carried out by the MCC at M-P (circled points in Fig. 6).

The accumulated Ti contents measured during the whole period are given in Fig. 7, where it can be seen that the trend for different materials was the same at both platforms, with smaller values observed for the materials at AR-P because the volume of the containers to collect the leachates was smaller. During episodes of heavy rain, the containers overflowed, so the volume considered to make the calculations was that of the full container. This caused the values in Fig. 6 to be underestimated and should therefore only be used for comparative purposes of the behaviour of the different materials, which was quite consistent between the two platforms.

To obtain real reference values, the concentration of $\mathrm{Ti}$ in the leachate was considered. The highest concentrations found for the different materials at M-P and AR-P are listed in Table 1, where the accordance between the platforms can be again observed for the different materials.

These results are in accordance with the wide variety of data reported in the literature, as under the same conditions independent of the level of efficiency, some products leached Ti while others did not. Beside this, there is no clear behaviour on the basis of the type of application (slurry, suspension or $\mathrm{TiO}_{2}$ built-in). This finding suggests that before a real implementation of photocatalytic materials, it is necessary to ensure that the material does not leach Ti nanoparticles into aqueous media. The significance of the levels of exposure has to be determined through toxicological studies, as will be discussed below.

Samples in which Ti was detected by ICP were deposited dropwise on amorphous carbon filters supported on copper transmission electron microscopy (TEM) grids or on aluminium TEM grids and were allowed to dry. Then, the morphology and chemical composition of the particles in the substrate were analysed using FE-SEM and EDX. Ti was only detected in two samples, which corresponded to materials $\mathrm{C}$ and $\mathrm{E}$ at AR-P (see Fig. 8). Fig. 8-a and d give a general view of the particles on the grid. The general image shows sparse micrometre-sized particles. Most of the observed particles had high contents of $\mathrm{Ca}, \mathrm{Al}, \mathrm{Si}, \mathrm{O}, \mathrm{Mg}$, $\mathrm{Na}, \mathrm{K}$ and other elements, which suggests that these particles mostly originated from the substrates of the materials. At higher magnification, fine and ultrafine particles could be distinguished. In some of them, seem as brighter points in Fig. 8-b and c, Ti nanoparticles could be detected attached to larger micrometre-sized particles (Fig. 8-c and f). No isolated Ti nanoparticles were detected. The release of $\mathrm{TiO}_{2}$ nanoparticles embedded into micro size particles of construction material matrix may prevent the potential harmful environmental and health effect of the isolated $\mathrm{TiO}_{2}$ nanoparticles.

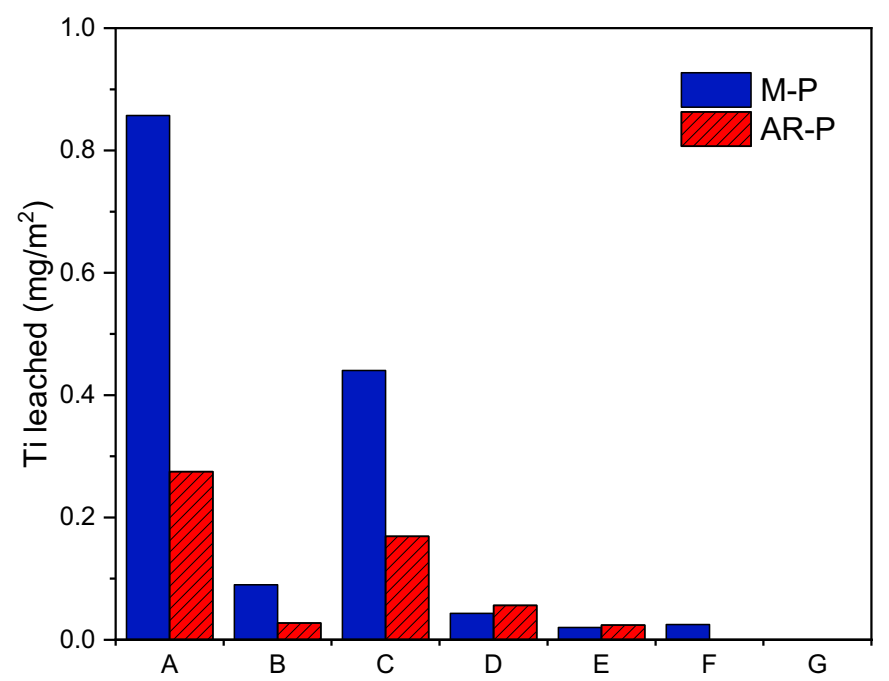

Fig. 7. Accumulated values of Ti leached $\left(\mathrm{mg} / \mathrm{m}^{2}\right)$ for the different materials on both localizations. 
Table 1

Highest leachate Ti concentrations $(\mu \mathrm{g} / \mathrm{L}$ ) observed for the different materials on platforms M-P and AR-P.

\begin{tabular}{lllllllll}
\hline Platform & A & B & C & D & E & F & G & Ref \\
\hline M-P & 42 & 9 & 48 & 28 & 2 & 11 & $<2$ & $<2$ \\
AR-P & 46 & 8 & 60 & 36 & 7 & $<2$ & $<2$ & $<2$ \\
\hline
\end{tabular}

\subsection{Leaching of nitrates}

The concentration of $\mathrm{NO}_{3}^{-}(\mathrm{ppm})$ in the leachates from the materials on both platforms are given in Fig. 9(a-b), where the events of highpressure water cleaning at M-P have been highlighted in yellow, and the upper value of the highlighted area represents the concentration of $\mathrm{NO}_{3}^{-}$in the recycled water used during cleaning. The mean value for rainwater is also given in the figure. It can be seen that the pattern of Fig. 9-a was clearly influenced by the amount of nitrates in the leaching agent; thus, further analysis on the leaching of nitrates will be carried out on the AR-P data (Fig. 9-b). From Fig. 9-b, it can be seen that the maxima concentration is at approximately the beginning of monitoring, between 200 and 350 days and at 600 days and no noticeable $\mathrm{NO}_{3}^{-}$leaching occurring between these time points. To discriminate the amount of $\mathrm{NO}_{3}^{-}$that originated from the photocatalytic oxidation of $\mathrm{NOx}$, the accumulated value of $\mathrm{NO}_{3}^{-}$collected from the reference slab was subtracted from the values of the leachate samples collected during the same period from the photocatalytic slabs, which were higher than the reference value for all materials. This result indicated that the excess nitrates might be assigned to the photocatalytic oxidation of atmospheric NOx. As the absolute $\mathrm{NO}_{3}^{-}$values were underestimated, as for $\mathrm{Ti}$, the results were normalized with respect to the material that leached the most $\mathrm{NO}_{3}^{-}$and are presented in Fig. 10-a.

Fig. 10-a shows that the largest amount of nitrates during the accumulated period (last 300 days) corresponded to the leachate from material E. The leached nitrate ranking of the samples was $\mathrm{E}>\mathrm{G}>\mathrm{D}>\mathrm{A}>\mathrm{C}>\mathrm{F}>\mathrm{B}$. During this final period, the increase in leached nitrates for the photocatalytic platforms in relation to the reference material ranged from $14 \%$ for material B to $77 \%$ for material $\mathrm{E}$.

The initial percentage of nitrogen oxide removal, $\mathrm{R}_{\mathrm{NOx}}(\%)$, for each material was determined according to the standard ISO 22197-1:2007. In addition, on-site measurements were performed at the platforms at different times using the PhotonSite prototype (Jiménez-Relinque et al., 2019). The normalized values of accumulated $\mathrm{NO}_{3}^{-}$versus $\mathrm{R}_{\mathrm{NOx}}$ for the initial values determined at the laboratory and for the values obtained in July 2018 (likely pre-activated by sunlight), within the period of the last 300 days for AR-P are presented in Fig. 10-b, illustrating that a positive relationship exists between the photocatalytic activity and the production of nitrates. The correlation coefficient is much better for that corresponding to on-site values.

\subsection{Overall behaviour}

First, it should be mentioned that the slabs on both platforms were subjected to semi-controlled conditions, and even though all water was driven to the sampling containers through a light slope, they were located in the open air and subject to uncontrolled and unforeseen events. At M-P, samples were taken for almost every rain event; even though the authors tried to collect the leachates as soon as possible, on several occasions (as heavy rain during weekends), the containers were full, and water had overflowed. It could have also been the case that some samples underwent partial evaporation, especially during the hotter months, as the sampling containers were not airtight. As the slabs were cleaned only by rain (and also by high-pressure water in the case of M-P), dirt, leaves and mud were occasionally present in the containers, which could have interfered with the measurements. Additionally, there are stray cats on the premises of the IETcc in Madrid, which were seen several times near the slabs. Therefore, attention must be paid to the tendencies and comparative values within each platform more than to specific values. On the other hand, it should be noted that effects on leaching, such as the abrasion of tires, aggressive detergents or other factors, were not considered.

A comparison of the data from the meteorological stations of M-P and AR-P indicated that even though there were small differences (data not shown), the locations were same geographical region, and the general trends were very similar. However, the concentration of $\mathrm{NO}_{2}$ was different between the two locations and was higher at M-P in Madrid than at AR-P in Arganda del Rey. The monthly average concentrations of $\mathrm{NO}_{2}$ in both locations (data taken from the air quality stations closest to both platforms) are presented in Fig. 11, where the relative humidity, total radiation and precipitation for Madrid are also given. Values of nitrates for both platforms $\left(\mathrm{mg} / \mathrm{m}^{2}\right)$ are depicted as isolated points. It should be noted that the meteorological station in the specific location of the platforms started to run in April 2017, so data corresponding to precipitation from 01/10/2016 to 31/03/2017 were taken from the nearest meteorological station in Madrid.

In addition to the data in Fig. 10-b, Fig. 11 shows that nitrate leaching is clearly related to the factors affecting the photocatalytic activity. During the periods corresponding to a high relative humidity and low solar irradiation on the platforms, almost no nitrates were leached (November to January), and the level of leached nitrates increased with increasing radiation and decreasing relative humidity (around March) with higher amounts of $\mathrm{NO}_{2}$. On the other hand, the total amount of nitrates
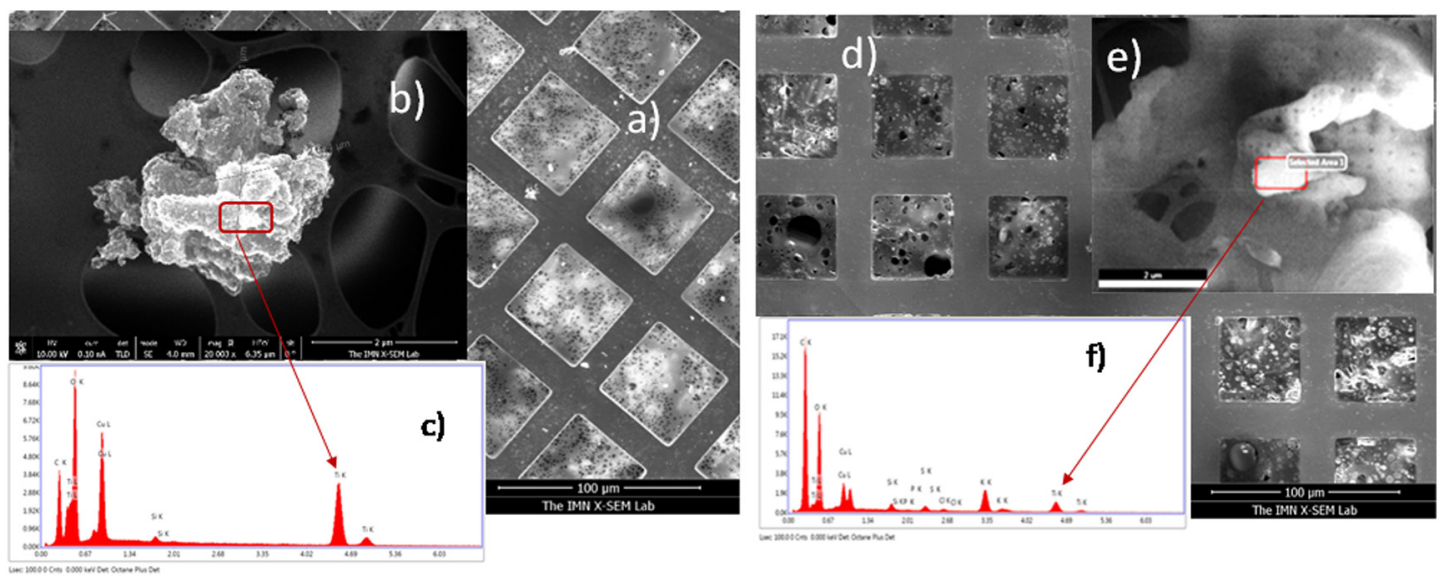

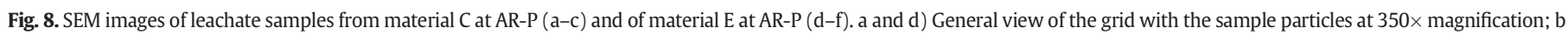
and e) particles that contained titanium; ( $c$ and f) EDX spectra of the areas marked in figures (b) and (e). 

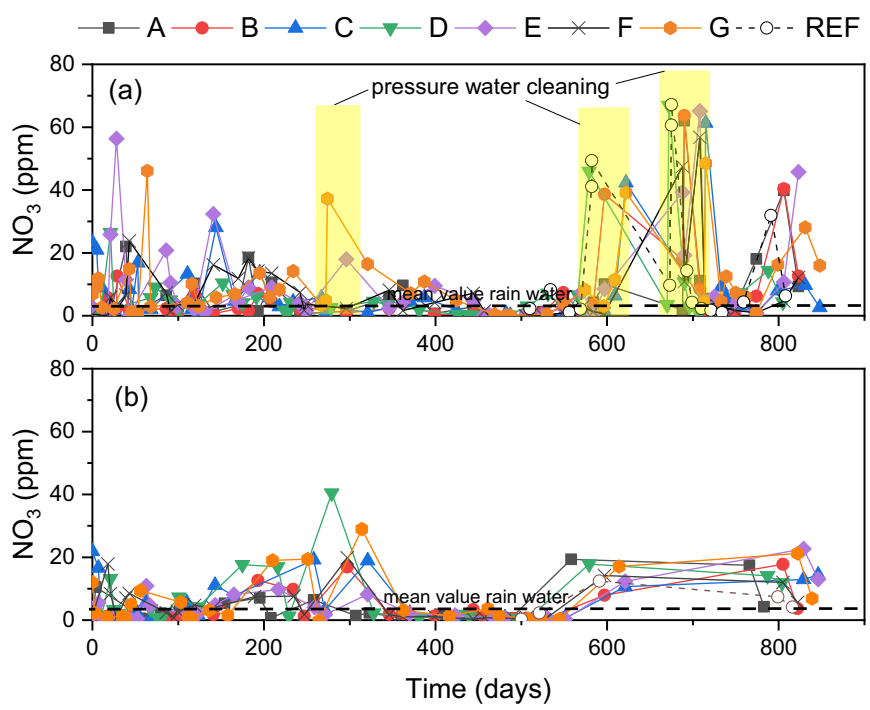

Fig. 9. Concentration of nitrates (ppm) in the leachates. a) M-P; b) AR-P. The events of high-pressure water cleaning in M-P are highlighted in yellow, the upper value of which is the concentration of $\mathrm{NO}_{3}^{-}$of the recycled water used during cleaning. The mean values obtained for rainwater are also shown.

decreased overall as the photocatalytic activity decreased over time (AlKattan, 2013). Additionally, in correspondence with the smaller amount of leached nitrates, the $\mathrm{pH}$ of the leachates increased during the periods of no photocatalytic activity, which might be attributed to the nonoccurrence of decomposition of water at the holes $\left(\mathrm{h}^{+}\right)$of photocatalyst, which led to the formation of $\mathrm{H}^{+}\left(\mathrm{H}_{2} \mathrm{O}+\mathrm{h}^{+} \rightarrow \cdot \mathrm{OH}+\mathrm{H}^{+}\right)$.

Leaching of Ti did not seem to be related to ageing factors, as Ti was only detected in the leachates during the first few days of monitoring. During the weathering and degradation of the materials, Ti was only detected when the materials were high-pressure water cleaned $(11 \mu \mathrm{g} / \mathrm{L}$ for material C after the first cleaning and $2 \mu \mathrm{g} / \mathrm{L}$ for materials $\mathrm{A}$ and $\mathrm{E}$ after the third cleaning). Concerning the effects of nano- $\mathrm{TiO}_{2}$ on humans and the environment, most references are found for airborne (D.-G.f.E. European Commission, 2020). Recently, the Committee for Risk Assessment in its Opinion of 14 September 2017 proposed to classify respirable $\mathrm{TiO}_{2}$ as carcinogen category 2 by inhalation to mixtures in powder form containing $1 \%$ or more of $\mathrm{TiO}_{2}$ which is in the form of or incorporated in particles with aerodynamic diameter $\leq 10 \mu \mathrm{m}$ (Nevshupa et al., 2020). In our best knowledge no normative references have been found on admissible limits for the concentration of Ti in water. According a compilation by ECHA (European Chemicals Agency) in July 2020 (ECHA, 2020), concerning aquatic toxicity, micro-and nano-TiO is not acutely and chronically toxic to aquatic organisms. Concerning sediments micro-and nano- $\mathrm{TiO}_{2}$ appear to have a low potential for acute and chronic freshwater and marine sediment toxicity based on data available for insect, crustacean and annelid species (ECHA, 2020). Concerning terrestrial toxicity, data from standard toxicity tests indicate that micro-and nano- $\mathrm{TiO}_{2}$ materials are not toxic to soil organisms including microbes, plants and invertebrates up to at least $1000 \mathrm{mg} / \mathrm{kg}$ soil (ECHA, 2020). Other authors found different results. Simonin et al. (2017) using soil microcosms, with nano- $\mathrm{TiO}_{2}$ concentrations ranging from 0.05 to $500 \mathrm{mg} / \mathrm{kg}$ dry-soil found that after 90 days of exposure, non-classical dose-response relationships were observed for nitrifier abundance or activity, making threshold concentrations impossible to compute even though significant reduction in the different colonies were found. Adams et al. (2006) found bacterial growth inhibition, in presence of nano- $\mathrm{TiO}_{2}$ even under dark conditions, highlighting the need for caution during the use and disposal of such manufactured nanomaterials to prevent unintended environmental impacts. Thus, as a normative reference, the Drinking Water Parameter Cooperation Project, in support of the revision of Annex I Council Directive 98/83/EC on the Quality of Water Intended for Human Consumption (Drinking Water Directive) published by the WHO (2017), can be used. This document stated that several emerging contaminants and groups of contaminants were considered but not given any parametric value because the data show that concern for health was highly unlikely. Among the contaminants considered, nanoparticles were included under the paragraph "While there are very few data to show that they reach drinking-water, there is some evidence that they would be removed in treatment (FERA, 2011). However, there are no appropriate means of measuring them or setting drinking-water standards at this time, but it would be appropriate to ensure that any proposals to include them in materials for use in contact with drinking-water should be assessed under a European approval scheme". As a matter of comparisons, according to WHO (2017) the parametric values for arsenic and chromium are 10 and $50 \mu \mathrm{g} / \mathrm{L}$, respectively. For copper, the parametric value is $2000 \mu \mathrm{g} / \mathrm{L}$. These values can be compared with those obtained for Ti in this research, which had a maximum concentration of $60 \mu \mathrm{g} / \mathrm{L}$.
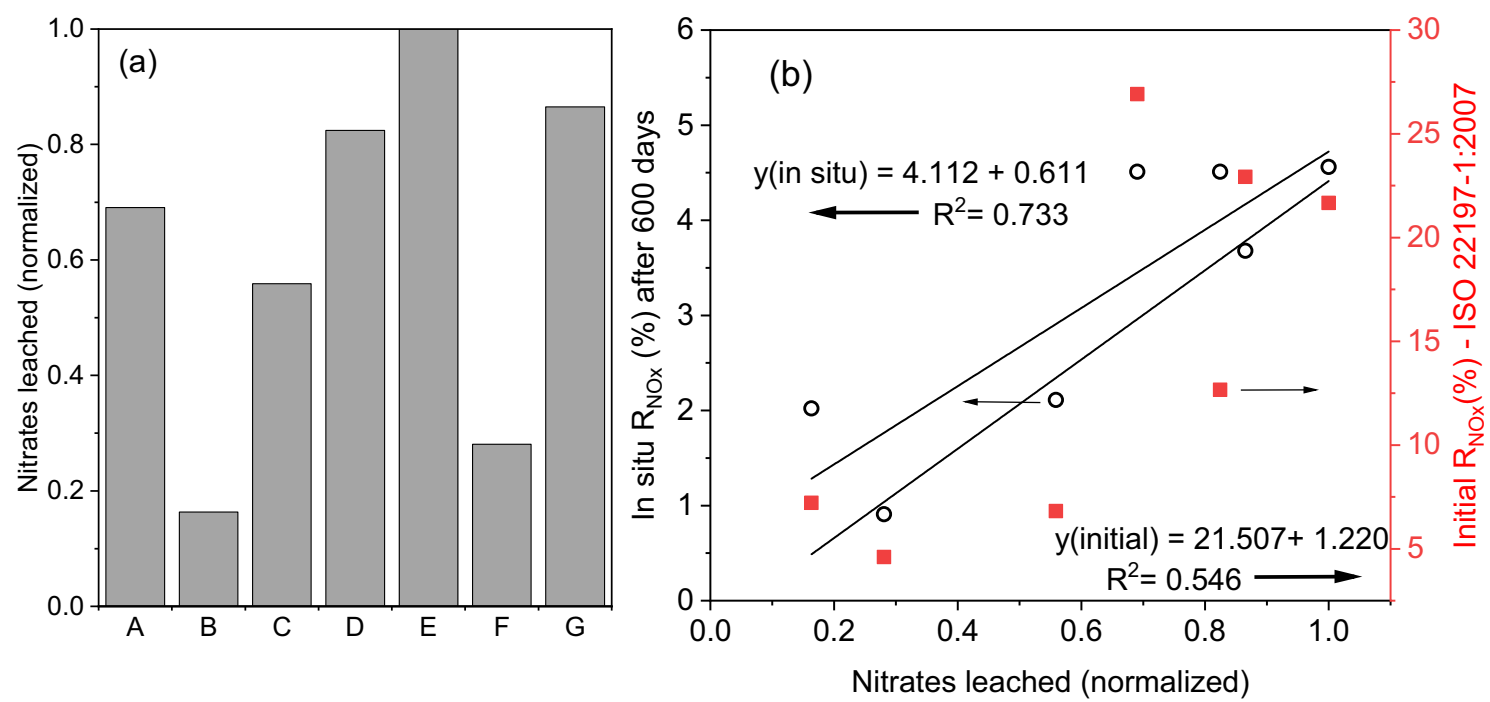

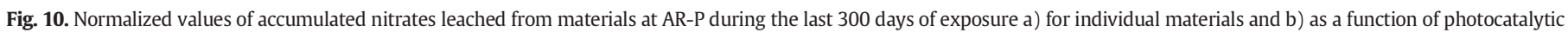
efficiency. 


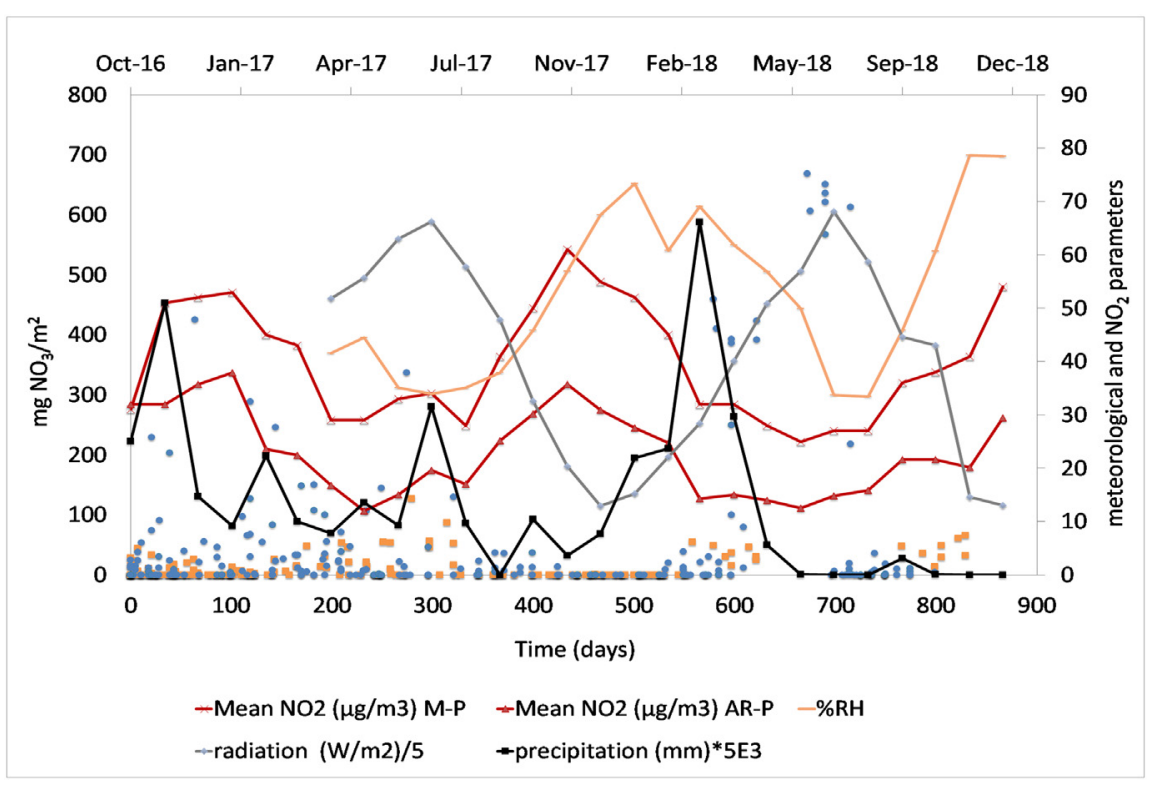

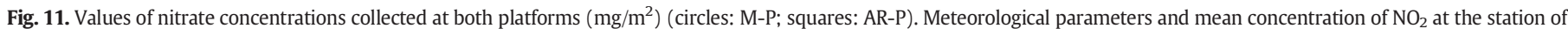
Madrid (continuous lines).

Concerning $\mathrm{NO}_{3}^{-}$, the relationship between the photocatalytic activity of the materials and an increase in nitrates in the runoff waters was clearly observed. In any case, the observed values were lower than that in the recycled water used to clean the streets of Madrid in the highpressure water process. According to the Directive 2006/118/EC on the protection of groundwater against pollution and deterioration, one of the criteria for groundwater quality standards is related to nitrates and is set to $50 \mathrm{mg} / \mathrm{L}$. This is also the threshold chemical reviewed by WHO in 2011. This threshold was never reached as a consequence of the photocatalytic activity of the materials tested (AR-P).

\section{Conclusions}

This paper presents a systematic and long-term study assessing the potential side effects associated with the use of photocatalytic construction technologies in outdoor environment. Leaching of Ti as well as nitrates generated by the photocatalytic oxidation of nitrogen oxides have been evaluated by analyzing the leachates coming from rainwater after lapping slabs of $2 \mathrm{~m} \times 2 \mathrm{~m}$ of 7 different materials exposed in two locations during more than 800 days. The following main conclusions have been derived:

- Almost every material released $\mathrm{TiO}_{2}$, not having found a clear behaviour with the type of photocatalytic material/application (slurry, suspension or $\mathrm{TiO}_{2}$ built-in). The higher concentration found was of $60 \mu \mathrm{g} / \mathrm{L}$ corresponding to a suspension coating while the highest accumulated amount corresponds to a cementitious slurry percolated on asphalt. One of the built-in $\mathrm{TiO}_{2}$ photocatalytic tile, presented always Ti values under the limit of detection of the analytic equipment used $(<2 \mu \mathrm{g} / \mathrm{L})$. Comparison of the concentration values found for Ti with the threshold limits for some metals for drinking water, the amount of Ti leached seems to be rather small.

- All the observed $\mathrm{TiO}_{2}$ nanoparticles in the leachates were embedded in large microparticle agglomerates of the construction matrix, which is less dangerous than release of nanoparticles.

- Leaching of Ti did not seem to be related to ageing factors, as Ti was only detected in the leachates during the first few days of monitoring.

- Nitrates were leached in clear relation with the nitrogen oxide photocatalytic oxidation performance. Even though, the concentration of nitrates found in the samples leached was mostly lower than what it is normally found in recycled waters, used for street cleaning by the Madrid City Council and other applications.

\section{CRediT authorship contribution statement}

Eva Jimenez-Relinque: Investigation, Writing - review \& editing, Visualization. Maria Grande: Investigation. Teresa Duran: Investigation. Ángel Castillo: Methodology, Investigation. Marta Castellote: Conceptualization, Methodology, Writing - original draft, Writing - review \& editing, Supervision.

\section{Declaration of Competing Interest}

The authors declare that they have no known competing financial interests or personal relationships that could have appeared to influence the work reported in this paper.

\section{Acknowledgements}

This study was funded by the LIFE programme (Project LIFE PHOTOSCALING, LIFE 13/ENV/ES/001221, http://www.life-photoscaling. $\mathrm{eu} / \mathrm{)}$. The authors wish to thank the Madrid City Council for their contribution to platform cleaning and the companies that supplied the photocatalytic products: Sociedad Financiera y Minera, S.A.; Active Walls, S.L.; Industrial Breinco, S.A.; Tronox France S.A.S.; Impresa Bacchi S.R.L.; GranitiFiandre S.p.A; and Fundación Cartif. The authors are grateful to L. Córdoba and F. Rubiano for their help in the collection of the leachates. The authors acknowledge the European Chemicals Agency, http://echa. europa.eu/ as a source of $\mathrm{TiO}_{2}$ toxicological data.

\section{References}

Adams, Laura K., Lyon, Delina Y., Alvarez, Pedro J.J., 2006. Comparative eco-toxicity of nanoscale $\mathrm{TiO}_{2}, \mathrm{SiO}_{2}$, and $\mathrm{ZnO}$ water suspensions. Water Res. 40 (19), 3527-3532 (ISSN 0043-1354). https://doi.org/10.1016/j.watres.2006.08.004.

Al-Kattan, A., et al., 2013. Release of $\mathrm{TiO}_{2}$ From Paints Containing Pigment-TiO ${ }_{2}$ or Nano$\mathrm{TiO}_{2}$ by Weathering. vol. 15(12). Environmental Science: Processes \& Impacts, pp. 2186-2193.

Ansari, A.A., et al., 2010. Eutrophication: Causes, Consequences and Control. vol. 1. Springer.

Bengtsson, N., Castellote, M., 2010. Photocatalytic activity for NO degradation by construction materials: parametric study and multivariable correlations. J. Adv. Oxid. Technol. 13 (3), 341-349. 
Bengtsson, N., Castellote, M., 2014. Heterogeneous photocatalysis on construction materials: effect of catalyst properties on the efficiency for degrading NOx and self cleaning. Mater. Constr. 64 (314), 013.

Bossa, N., et al., 2017. Environmental Exposure to $\mathrm{TiO}_{2}$ Nanomaterials Incorporated in Building Material. vol. 220 pp. 1160-1170.

Buzea, C., Pacheco, I.I., Robbie, K., 2007. Nanomaterials and Nanoparticles: Sources and Toxicity. vol. 2(4). Biointerphases, pp. MR17-MR71.

Bystrzejewska-Piotrowska, G., Golimowski, J., Urban, P.L., 2009. Nanoparticles: Their Potential Toxicity, Waste and Environmental Management. vol. 29(9). Waste Management, pp. 2587-2595.

Cannavale, A., et al., 2010. Multifunctional Bioinspired Sol-Gel Coatings for Architectural Glasses. vol. 45(5) pp. 1233-1243.

Cassar, L., 2004. Photocatalysis of cementitious materials: clean buildings and clean air. MRS bulletin 29 (5), 328-331.

Chapman, P.M., 2006. Emerging Substances-Emerging Problems? vol. 25(6). Environ. Toxicol. Chem, pp. 1445-1447

D.-G.f.E. European Commission, 2020. In: ENV (Ed.), Commission Delegated Regulation (EU) 2020/217 of 4 October 2019 Amending, for the Purposes of Its Adaptation to Technical and Scientific Progress, Regulation (EC) No 1272/2008 of the European Parliament and of the Council on Classification, Labelling and Packaging of Substances and Mixtures and Correcting That Regulation (Text With EEA Relevance). European Commission, Brussels.

Chen, J., Poon, C., 2009. Photocatalytic Cementitious materials: Influence of the Microstructure of Cement Paste on Photocatalytic Pollution Degradation. vol. 43(23). Environ. Sci. Technol., pp. 8948-8952.

Devahasdin, S., et al., 2003. $\mathrm{TiO}_{2}$ Photocatalytic Oxidation of Nitric Oxide: Transient Behavior and Reaction Kinetics. vol. 156(1-3) pp. 161-170.

Diamanti, M., et al., 2013. Photocatalytic and self-cleaning activity of colored mortars containing $\mathrm{TiO}_{2}$. Constr. Build. Mater. 46, 167-174.

Dillert, R., et al., 2013. Light Intensity Dependence of the Kinetics of the Photocatalytic Oxidation of Nitrogen (ii) Oxide at the Surface of $\mathrm{TiO}_{2}$. vol. 15(48) pp. 20876-20886.

Dwivedi, A.D., et al., 2015. Fate of engineered nanoparticles: implications in the environment. Coord. Chem. Rev. 287, 64-78.

Dylla, H., Hassan, M.M., 2014. Potential of nanoparticles and nitrates released to water from photocatalytic pavements. Construction Research Congress 2014: Construction in a Global Network.

ECHA, 2020. European chemicals, agency. https://echa.europa.eu/registration-dossier/-/ registered-dossier/15560/6/2/1.

Federici, G., Shaw, B.J., Handy, R.D., 2007. Toxicity of Titanium Dioxide Nanoparticles to Rainbow Trout (Oncorhynchus mykiss): Gill Injury, Oxidative Stress, and Other Physiological Effects. vol. 84(4). Aquatic Toxicology, pp. 415-430.

FERA, 2011. Review of the risks posed to drinking water by man-made nanoparticles. Report DWI 70/2/246 by the Food and Environment Research Agency for the Drinking Water Inspectorate. Available at:. http://dwi.defra.gov.uk/research/completed-research/reports/DWI70_2_246.pdf.

Folli, A., et al., 2009. Rhodamine B Discolouration on $\mathrm{TiO}_{2}$ in the Cement Environment: Look at Fundamental Aspects of the Self-cleaning Effect in Concretes. vol. 12(1) pp. 126-133.

Folli, A., et al., 2012. $\mathrm{TiO}_{2}$ photocatalysis in cementitious systems: insights into selfcleaning and depollution chemistry. Cem. Concr. Res. 42 (3), 539-548.

Fujishima, A., Honda, K., 1972. Electrochemical Photolysis of Water at a Semiconductor Electrode. vol. 238(5358). Nature, p. 37.

Gibson, B., Badiei, H.R., Karanassios, V., 2006. Ti in Dilute Slurries of $\mathrm{TiO}_{2}$ Nanoparticles by in-torch Vaporization Sector Field Inductively Coupled Plasma-Mass Spectrometrys vol. 61(6). Spectrochimica Acta Part B: Atomic Spectroscopy, pp. 753-758.

Goodall, P., Foulkes, M.E., Ebdon, L., 1993. Slurry Nebulization Inductively Coupled Plasma Spectrometry-The Fundamental Parameters Discussed. vol. 48(13). Spectrochimica Acta Part B: Atomic Spectroscopy, pp. 1563-1577.

Goswami, D., Trivedi, D.M., Block, S.S., 1997. Photocatalytic Disinfection of Indoor Air. vol. 119(1). J. Sol. Energy Eng., pp. 92-96.

Halicz, L., Brenner, I.B., Yoffe, O., 1993. Direct Solids Analysis of Geological Samples Using Slurry Nebulization Inductively Coupled Plasma Atomic Emission Spectrometry. vol. 8(3). J. Anal. At. Spectrom., pp. 475-480.

Hassan, M., et al., 2012. Nitrogen oxide reduction and nitrate measurements on $\mathrm{TiO}_{2}$ photocatalytic pervious concrete pavement. Construction Research Congress 2012: Construction Challenges in a Flat World.
Herrmann, J.M., 1999. Heterogeneous Photocatalysis: Fundamentals and Applications to the Removal of Various Types of Aqueous Pollutants. vol. 53(1). Catalysis Today, pp. 115-129.

Hüsken, G., et al., 2009. Experimental Study of Photocatalytic Concrete Products for Air Purification. vol. 44(12). Building and Environment, pp. 2463-2474.

Jayapalan, A.R., Lee, B.Y., Kurtis, K.E., 2013. Can nanotechnology be 'green'? Comparing efficacy of nano and microparticles in cementitious materials. Cem. Concr. Compos. 36, $16-24$.

Jimenez-Relinque, E., Castellote, M., 2014. Influence of the inlet air in efficiency of photocatalytic devices for mineralization of VOCs in air-conditioning installations. Environ. Sci. Pollut. Res. 21 (19), 11198-11207.

Jimenez-Relinque, E., et al., 2016. Photocatalytic decomposition of pollen allergenic extracts of Cupressus arizonica and Platanus hybrida. Chem. Eng. J. 286, 560-570.

Jiménez-Relinque, E., et al., 2019. In Situ Evaluation of the NOx Removal Efficiency of Photocatalytic Pavements: Statistical Analysis of the Relevance of Exposure Time and Environmental Variables. pp. 1-8.

Kägi, R., et al., 2008. Synthetic $\mathrm{TiO}_{2}$ Nanoparticle Emission From Exterior Facades Into the Aquatic Environment. vol. 156(2) pp. 233-239.

Lovern, S.B., et al., 2007. Behavioral and Physiological Changes in Daphnia magna when Exposed to Nanoparticle Suspensions (Titanium Dioxide, Nano-C60, and C60HxC70Hx). vol. 41(12) pp. 4465-4470.

Nevshupa, R., et al., 2020. Assessment of urban air pollution related to potential nanoparticle emission from photocatalytic pavements. J. Environ. Manag. Under revision for minor changes.

Olabarrieta, J., et al., 2012. Aging of Photocatalytic Coatings under a Water Flow: Long Run Performance and $\mathrm{TiO}_{2}$ Nanoparticles Release. vol. 123 pp. 182-192

Pacheco-Blandino, I., Vanner, R., Buzea, C., 2012. Toxicity of nanoparticles. Toxicity of Building Materials. Elsevier, pp. 427-475.

Pacheco-Torgal, F., Jalali, S., 2011. Nanotechnology: Advantages and Drawbacks in the Field of Construction and Building Materials. vol. 25(2). Construction and Building Materials, pp. 582-590.

Peruchon, L., et al., 2009. Photocatalytic Efficiencies of Self-cleaning Glasses. Influence of Physical Factors. vol. 8(7) pp. 1040-1046.

Sánchez, B., et al., Photocatalytic oxidation of chlorinated hydrocarbons with $\mathrm{TiO}_{2}$ on magnesium silicate monoliths.

Sapiña, M., et al., 2013. Controlling the Levels of Airborne Pollen: Can Heterogeneous Photocatalysis Help? vol. 47(20) pp. 11711-11716

Sapiña, M., et al., 2017. Degradation of pollen on nanofunctionalized photocatalytic materials. J. Chem. Technol. Biotechnol. 92 (1), 210-216.

Shandilya, N., et al., 2015. Emission of Titanium Dioxide Nanoparticles From Building Materials to the Environment by Wear and Weather. vol. 49(4) pp. 2163-2170.

Sikora, P., et al., 2017. The Effects of Silica/Titania Nanocomposite on the Mechanical and Bactericidal Properties of Cement Mortars. vol. 150 pp. 738-746.

Simonin, Marie, Martins, Jean M.F., Le Roux, Xavier, Uzu, Gaëlle, Calas, Aude, Richaume, Agnès, 2017. Toxicity of $\mathrm{TiO}_{2}$ nanoparticles on soil nitrification at environmentally relevant concentrations: lack of classical dose-response relationships. Nanotoxicology 11 (2), 247-255. https://doi.org/10.1080/17435390.2017.1290845.

Smits, M., et al., 2013. Photocatalytic Degradation of Soot Deposition: Self-cleaning Effect on Titanium Dioxide Coated Cementitious materials. vol. 222 pp. 411-418.

Wang, Z., et al., 2005. Direct Determination of Nb in Titanium Oxide Using Slurry Sample Introduction by Axial Viewing Inductively Coupled Plasma Optical Emission Spectrometry. vol. 25(4) pp. 556-559.

WHO, 2017. Drinking Water Parameter Cooperation Project. Support to the Revision of Annex I Council Directive 98/83/EC on the Quality of Water Intended for Human Consumption (Drinking Water Directive) Recommendations (September).

Wu, D., et al., 2007. Determination of Impurities in Magnesium Niobate by Slurry Introduction Axially Viewed Inductively Coupled Plasma Optical Emission Spectrometry. vol. 389(6) pp. 2003-2008.

Zhu, W., Bartos, P.J., Porro, A., 2004. Application of nanotechnology in construction. Mater. Struct. 37 (9), 649-658

Zuin, S., et al., 2014. Leaching of Nanoparticles From Experimental Water-borne Paints Under Laboratory Test Conditions. vol. 16(1) p. 2185. 